[PENUlTimATE DRAFT. PleASE GITE THE PUBLISHED VERSION:

Journal of Aesthetics and Art Criticism 74 (2): 191-195. 2016]

\title{
Using the Street for Art: A Reply to Baldini
}

\section{Nick Riggle}

In his discussion of my 2010 "Street Art: The Transfiguration of the Commonplaces," Andrea Baldini makes some excellent points about street art and the ownership of public space. But if I understand him correctly, then I disagree with his core claims. I take his core claims to be that (1) street art is essentially subversive; and (2) its subversiveness consists in its challenging the co-opting of public space by visual commercial culture.- I think both claims are incorrect. In my view, street art is not essentially subversive, and when it is, it is not always in virtue of its challenging the commercial use of public space. However, although I don't think Baldini has located a fact about street art's essence, I think he is right to focus on this aspect of street art's importance, for it reveals something about its essence.

In my original definition of street art-roughly, art whose use of the street is essential to its artistic meaning-I was explicitly vague about what counts as "the street”. Initially I wrote that it was “any urban public space," but I was compelled to say more when considering the relation between street and "public" art. Here's what I wrote:

"For a place to be the street, people must treat it as the street, which means they must maintain a vague constellation of practical attitudes toward it. It is difficult to say what these attitudes are and which are more central than the others. One 
important attitude seems to be the consideration of a space as social... Another important attitude seems to be the belief that the space is primarily public, that it is basically for-the-public.” (255)

This still leaves fairly open the question of what exactly "the street" is. I want to say more about the idea that the street is a public, social space by distinguishing two notions of "the street" and elaborating on one of them.

Often when we think of the street, we have in mind a spatial or logistical notion. We have to move from one place to another, and the street is a space whose function it is to facilitate travel by car, foot, bike, and so on. In this sense, the street is a space that facilitates (land) travel. This includes Wall Street and the Champs-Élysées, but also highways, rural roads, and small town lots.

But another sense of "the street" is socio-cultural. According to this conception, the street is a public space that has a certain cultural function. In this sense, many spaces that facilitate travel are not the street: rural country roads and massive highways, for example. So having the function of facilitating travel is not sufficient for being the street in this sense. Nor is it necessary: town squares, parks, narrow alleys, and other spaces can be the street in the socio-cultural sense without having the function of facilitating travel (even if they do in fact facilitate it).

So what makes something "the street" in this latter sense? What exactly is the “cultural function” of the street? Consider an oppressive public square where people's actions are severely restricted by law. Suppose they are only allowed to wave hello and goodbye. Or consider a sidewalk where no one is allowed to look another person in the eye. Neither of these spaces is the street in the cultural sense because they severely limit interaction. People are unable to engage with one another, express themselves, or do 
anything other than the legislated actions.

If a space loses its status as the street when actions are severely restricted, then it seems that one of the important functions of the street is to facilitate certain kinds of action. This suggests that the street in this latter sense-let's call it the cultural street - should be understood partially in terms of norms of action and interaction. But what kind of action? And what are the norms?

Consider a public space where people can talk to one another, but everyone must wear yellow, or speak in monotone, or stand on their tippy-toes. Although interaction is allowed, it is severely restricted by these constraints, and this seems incompatible with being the street. But why? The constraints severely limit self-expression. If I'm always wearing yellow, I can’t wear pink and black; if I'm always standing on my tippy-toes, I can’t swagger or skip.

Now consider a public space where people can talk to one another, but they cannot play extremely loud music, or they cannot spit gum onto the sidewalk. These actions are low on the scale of self-expressiveness, and they can restrict the ability of others to express themselves. If the music is too loud, then no one can hear anything; if there's gum everywhere, then no one can dance. Yet we still consider public spaces that contain these restrictions to be the street.

These considerations suggest that the kind of action the cultural street facilitates is self-expression, along with the interactions that can result when selves are expressive. The norm that governs such interaction is just the norm that, within reason, anything goes. The street facilitates self-expression and public interaction in a relatively constraint-free way. For this reason, the cultural street can play an important role in a free society. It doesn't just allow us to get from one place to another-it allows us to 
express ourselves, and to recognize, confront, and appreciate one another. It's a place where we can express ourselves in public, present our style, declare our commitments, allegiances, and values — where we can be seen for who we are or aspire to be.

Thus we have two ways of thinking about the street — one emphasizes a logistical function, while the other emphasizes a socio-cultural function. When I say that street art is art whose use of the street is essential to its meaning, I have in mind the sociocultural notion of the street. Street art uses a space whose function it is to facilitate selfexpression in a way that is essential to its artistic meaning. In other words, street art is art that uses the street as such, that is, as a cultural space that facilitates self-expression.

With this in mind, we can examine Baldini’s core claims. Let's consider the more specific claim first, namely, that street art essentially challenges the use of public space for visual advertising. Baldini's argument for this is puzzling. He points out, rightly in my view, that there is a tension between street art and commercial art. If a work is public commercial art, then its status as street art is compromised. But he seems to think that it follows straightforwardly from this that if a work is street art, then it must subvert the commercial use of public space.- But that's a non-sequitur. Consider an analogy: there is a tension between abstract and representational painting - a painting that realistically depicts the natural world is (for that reason) not abstract. But it does not follow that every abstract painting somehow calls into question the legitimacy of representational painting (even if, as a matter of historical fact, abstract painting arose in opposition to representational painting).

Setting this aside, it is unclear what exactly Baldini wants to establish. There are two ways of reading his claim, one "intentional" and another "non-intentional". On the intentional reading, Baldini's claim is that street artists intend for their art to challenge 
the commercial use of public space. Baldini is right to claim that confronting the commercial use of public space is an important motivation for many street and graffiti artists. But it obviously doesn't motivate them all—street artists, like all artists, have extremely diverse motivations.

So perhaps Baldini has in mind a non-intentional reading. Perhaps he means that all street art has the effect of challenging the commercial use of public space, whether or not street artists seek this effect. Or perhaps he means that street art merits consideration

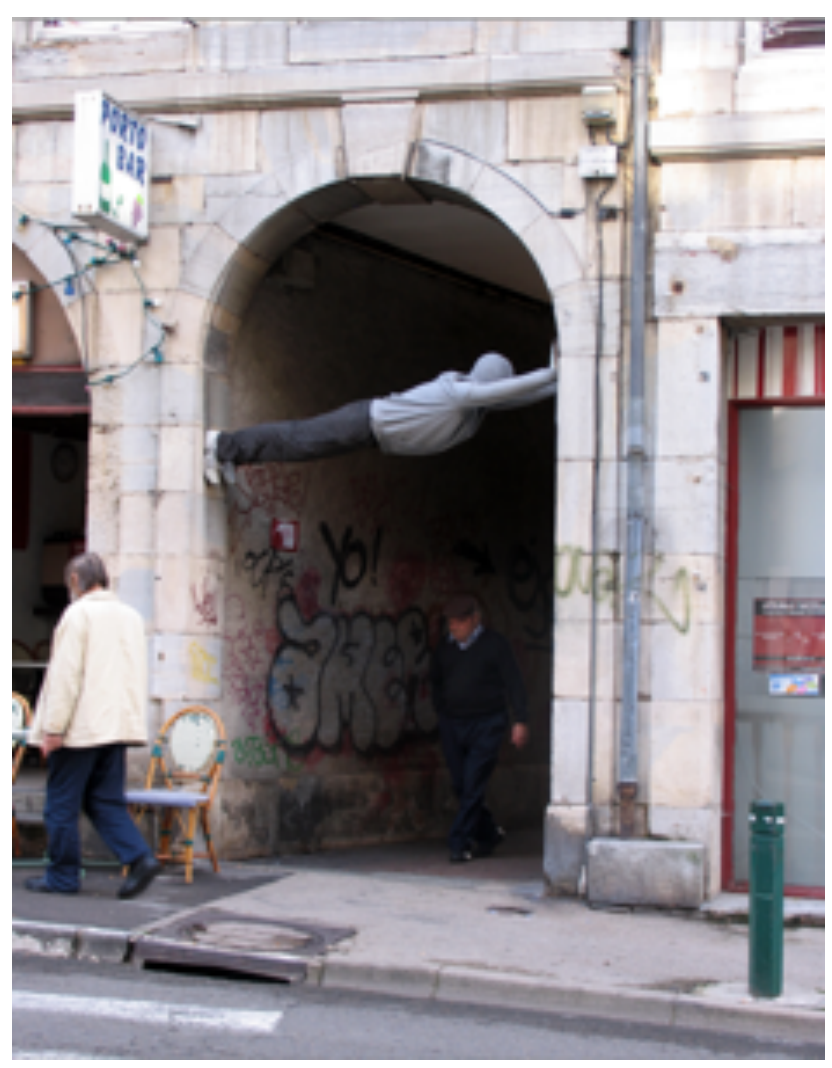
of the commercialization of public space, whether or not the artist intends it to. I will lump these two ideas into the "import" of street art. The non-intentional reading of Baldini's claim, then, is that street art's import is essentially about the commercialization of public space. The problem with the non-intentional claim is that many street artists create works in places that are not dominated by advertisements-parks, alleyways, neglected buildings, construction sites - and the import of many of these works has nothing to do with commercial culture. Consider some of Mark Jenkins’s street sculptures.

These works concern, in part, the “...norms and conventions regulating acceptable uses of public space," (XXX) but it takes a pretty elastic imagination to see 
their import as being specifically about commercial culture.

Even if street art does not essentially challenge public commercial visual culture, perhaps Baldini is right to say that street art is more generally subversive. A subversive art, I take it, is one that attempts to undermine the dominance or power of an established system or institution. Baldini emphasizes the institutions of public commercial visual culture, but taken more broadly we can include the art and gallery worlds, capitalism, more local systems and practices, and so on. In Riggle 2010 I argued that street art is essentially antithetical to the art world because it cannot easily, if at all, be incorporated into the art world's institutions of preservation, display, history, and appreciation. If this means that all street art is subversive with respect to the art world status quo, then to that extent I agree with Baldini. However, one thing can be antithetical to another without subverting it. Not all opposition is undermining.

Putting the antithetical character of street art aside, I do not think it's true that all street art is subversive. Often what matters is the way that street art harnesses and augments the essential function of the street. Some street art uses the street as such-as a space that facilitates self-expression-and facilitates it further.

Consider Bruno Taylor's "Bus Stop Swings"-swings installed at boring bus stops_-or, to use an example from Riggle 2010, C. Finley's "Wallpaper Dumpster" project in which she beautified hideous city dumpsters. On a natural reading of these works - and there are many other examples — they aren't subversive so much as visionary. They don't necessarily undermine the dominant forms of bus stop or dumpster design so much as propose ways of achieving the goals of good urban design. They show us forms of urban life that are within our grasp. Or, in other words, they show us how well the cultural street can realize its function. The prevalence of commercial visual 
culture need have nothing to do with it. (And note that for the purposes of this argument, it doesn't matter what these artists' actual intentions are. What matters is that it's compatible with a good notion of street art that these be their intentions.)

So I sympathize with Baldini when he writes that street art “...challenges norms and conventions regulating acceptable uses of public space.” (XXX) But this doesn't mean that such works “...disrupt the nature of those locations by altering significantly (some of) their expected uses." (XXX, my emphasis) The "nature" of the location is given by its status as the street—or more particularly as a bus stop-which is the very thing that must remain intact for the art to function as street art. Of course, the bus stop doesn't remain entirely the same. It is by altering features of the practical character of the bus stop that Bruno Taylor shows us what a really good bus stop might look like.

Baldini is right to note that the commercial use of public space can undermine that space in a way that calls for the public to reclaim it. All the better if their mode of reclamation is art. The street is a delicate thing that can be easily exploited and destroyed. In fact, street artists themselves can destroy it. Understanding this aspect of street art helps us see what makes street art distinctive, and it reveals some of the special challenges street artists face in making their art.

A space can be more-or-less the street, depending on the degree to which it facilitates public interaction by facilitating self-expression. That's a function a space can have to a greater and lesser extent, and it's a function a space can lose. And since, in my view at least, the street is the medium for street art, street art is artistically fragile. An artform is fragile if and only if the artistic use of its medium can undermine the art. Painting, for example, is not artistically fragile because the artistic use of paint results in artistic painting. (It might not be very good, but that's another issue.) The artistic use of 
the active human body results in dance. The artistic use of space and volume results in sculpture. And so on.

Street art seems special in its fragility. The artistic use of the street can change the nature of the space the art purports to use, and so can undermine itself in the production of street art. This seems to happen most dramatically with hype and fame. When street artists become so famous that hordes flock to see, protect, or steal whatever they have produced, there is a danger that by putting art in the street the artist will transform the function of that public space and thereby undermine their art. Street artists must negotiate a balance between the art of the street and the life of the street, so that the two are integrated and enhanced. Street art's power lies in its ability to harness the function of the street without destroying it. In this way, street art is the art of the street, in the same sense that sculpture is the art of space and volume, and dance the art of the active human body.

For this reason, I think that street art will always have a place in societies like ours-among free, expressive, and public beings. Yet Baldini's view suggests that street art would vanish along with commercial visual culture. The problem is that Baldini ties street art's cultural importance too closely to visual culture. A case in point:

Street art does not reinforce but rather questions habitual modes of thinking and acting. By intruding into the urban texture, it challenges our unexamined assumptions about visibility in public spaces, shaking our ways of thinking about the city. (XXX)

Here Baldini moves from an apt thought about street art's ability to address our habitual modes of thinking to the questionable thought that it does so by challenging assumptions about visual culture. But street art's importance is not limited to 
maintaining a healthy public visual culture-its importance lies in the value of our public sociality. Just as there will always be room for an art of human movement or of space and form, there will always be room for an art of self-expressive public space in free societies - an art that we cannot achieve by merely putting art in public space. We need to be reminded of, and reinvigorated toward, the importance of the street by creative or improvisational gestures that take up, promote, or enhance the aims of public space. Battling the dominance of commercial visual art is an important way to do this, but it is by no means the only way.

None of this is intended to ignore or downplay the importance of street art's tradition of challenging commercial visual culture - a tradition that is alive and well and welcome. (And one that somebody could write a good book about.) But as I have argued, leveraging it into an essential condition of street art is a mistake.

Lastly I'll note that Baldini reads more than is merited into my 2010 discussion of "disinterest" and quotes me in a way that is misleading (XXX). In Riggle 2010 I point out that, ironically for formalists, street art is perhaps best at "lifting us out of the everyday" - a kind of experience that formalists loved to emphasize. But I didn't write this by way of endorsing the idea that our experience of street art is disinterested. I also wrote that “...it is impossible to employ solely formalist principles in a critique of street art” (249), and as I explain on the same page, the proper experience of street art cannot be "disinterested". Often when experiencing street art

One is jolted out of whatever hazy cloud of practical thought one was in; one is forced to reconsider one's purely practical and rather indifferent relationship to the street, and a curiosity to explore the work develops. However, the experience is not, contrary to formalism, the primary ground for a critical opinion. Criticism 
appropriate to street art requires further consideration of the work's meaning, especially the significance of its use of the street. (249)

Baldini seems to ignore this when he goes on to write, as if in opposition to my view:

When acknowledging its role in our everyday lives, it clearly appears that street art's appreciation cannot be limited to a disinterested contemplation of beautiful forms. In order to fully grasp its value, a viewer needs to attend to its essential subversive function, and to grasp how it challenges dominant uses of public space, in particular those of a commercial nature. (XXX)

As Baldini himself notes, and as I hope my discussion has made clear, I think it's essential to street art criticism that we take into account the specific way it uses the street. This is incompatible with standard accounts of formalist criticism that are so fond of "disinterest," exclusive attention to form, and so on-an approach to criticism and the general theory of beauty that I don't find very promising. ${ }^{1}$ The point I make in Riggle 2010 is one that Baldini seems to agree with, namely, that street art can snap us out of a certain habitual mode of experience and engagement—one that can easily obscure subtle facts about our attitudes toward public space. Street art can strike us as mysterious, beautiful, exciting, or even visionary in a way that gets us to engage with the true function of the street — not just to get us to work or to the next appointment, but to facilitate the expression of the self that we all too easily forget to express.

\footnotetext{
${ }^{1}$ For a detailed discussion and critique of "disinterest" in the theory of beauty see my "On the Interest in Beauty and Disinterest," forthcoming in Philosophers' Imprint.
} 